\title{
Gelatin, halal or haram?
}

\author{
Hossein Elyasi ${ }^{1}$, Hadis Rahimi' ${ }^{1}$ Asghar Sepahvend ${ }^{2 *}$ \\ ${ }^{1}$ Student Research Committee, Faculty of Medicine, Lorestan University of Medical Sciences, Khorramabad, Iran \\ ${ }^{2}$ Razi Herbal Medicines Research Center, Lorestan University of Medical Sciences, Khorramabad, Iran
}

\section{*Correspondence to: \\ Dr. Asghar Sepahvand \\ fungimed44@yahoo.com}

Received: 28 September 2019

Accepted: 18 April 2020

ePublished: 16 June 2020

Keywords: Gelatin, medicine, Haram, Halal, Medicinal herbs, Quran

\section{Citation:}

Elyasi H, Rahimi H, Sepahvand A. Gelatin, halal or haram?. Plant Biotechnology Persa. 2020; 2(1): 35-41.

\section{Abstract}

Gelatin is a solid and transparent material that has wide application in various industries, especially for the production of food and pharmaceutical. This material is mainly made from meat, skin and bones of pigs and cows around the world. The industrial process of gelatin production is a long and costly process Also; these sources of gelatin production are prohibited in many religions and cultures in the world and they have a lot of health hazards. Therefore, this study was aimed at reviewing the alternative sources of gelatin production and the disadvantages and benefits of each of them. Relevant articles were searched from Google Scholar, PubMed, Scopus, Science direct, and Cochrane library. According to the results of this article, gelatin with a source of animal can have many harmful effects on human health. While it is possible to produce good and useful gelatin using plant sources. Almighty Allah has always recommended humans to consume halal foods while avoiding haram foods. Extensive research is required from the Islamic world to replace haram products with halal and Islamic products. Nowadays, from materials such as agar, pectin, carrageenan and konjac that are mentioned above, and as well as other materials, very good gelatins are prepared. And further researches are needed to find the rich sources of good gelatins or to find plants that have appropriate gelatin.

\section{Introduction}

Gelatin is a solid, transparent or semi-transparent substance, colorless, in (when it is dry) and more or less tasteless that comes mainly from collagen in the skin, flesh and bones of animals [1]. It is commonly used as a jelly agent in the food, pharmaceutical, photographic and cosmetic industries. Gelatin is mainly an unmodified hydrolyzed form of collagen in which the collagen protein is converted to smaller peptides and has a wide molecular weight range in relation to physical and chemical methods of denaturation based on what kind of hydrolysis process is used in gelatin production [2, 3]. Gelatin is used to make some sticky candy and products such as jelly, marshmallow, some low-fat yogurt, and also in the production of jelly fun, gelatinous desserts, some types of ice cream and making dipping sauce. Gelatin is used as a clearing agent in many beverages, volatile plasma, and stabilizer in many vaccines and in many other products. Gelatin is available in forms of sheet, granule or mainly powder [47]. Gelatin is a mixture of peptides and proteins that are made of collagen hydrolysis made from bone, skin, and connective tissue of animals such as pigs, cows, fishes, and chickens. In the gelatin structure, the links between each collagen fiber are broken and reconstruct easier [8].

In 2016, worldwide gelatin production is reported to be around 400,000 tons per year [9]. Gelatin is a byproduct of the meat and leather industry and fish have recently been considered as one of its sources of production. The raw material for the production of gelatin is stored in a variety of ways and are processed and extracted by various processes by using either from acid or from alkali or both, or from enzymatic processes. Generally, the process of preparing gelatin from animal sources, that most important of which is the skin, flesh and bone of pig, lasts for several weeks [10-12]. In the pharmaceutical industry, gelatin is mainly used to make hard and soft capsules and also as a very useful material for the production of pills, emulsions, suppositories and syrups [13]. In total, gelatin is introduced safe by the FDA. Most of the amino acids needed in the body are present in gelatin and there are not just sulfur containing amino acids. In total, in gelatin, there are 18 types of amino acids, and of 10 amino acids needed for

Copyright (C) 2020 The Author(s). This is an open-access article distributed under the terms of the Creative Commons Attribution License (http://creativecommons.org/licenses/by/4.0), which permits unrestricted use, distribution, and reproduction in any medium, provided the original work is properly cited. 
the body, 9 are in gelatin $[14,15]$. Gelatin is also used in industries such as adhesives, military industries, banknote paper making, moisture absorption, and so on. Gelatin-based adhesives are used to attach two organic pieces, such as fruits and vegetables. Also in the textile industry, gelatin is used as a material for shining, coating, cotton, leather, silk and wool fulfillment. In paper industry, gelatin is used to produce carbon paper and in the photographic industry to produce photo paper (black and white), as well as film production ( $35 \mathrm{~mm}$ films, APS, movie production, radio lagging, etc.) [16-19].

The use of gelatin prepared from some animal sources in some religions and cultures is prohibited. For example, eating gelatin prepared from a swine source is forbidden in the religion of Islam and Jews. The people of Rome have a lot of caution in taking gelatin because eating gelatin with a horse source in their culture is forbidden. In addition, many people around the world are vegetarians (Vegans) like many Hindus that do not use gelatin with an animal source, even non-vegetarian Hindus do not use cow gelatin because they regard the cow as sacred [20-22]. So far, alternatives to animal gelatin such as agar, carrageenan, pectin, Konjac, etc. have been identified. The biggest problem with these gelatins that has not been able to replace them with animal gelatin has been the lack of cost-effective and unavailable sources of them [23].

The use of pork in Islam and some other religions and cultures as a source of food is prohibited. Allah has forbidden in the Qur'an explicitly eating pork, for example, in verse 173, Surah Baqara says: )) He has only forbidden to you dead animals, blood, the flesh of swine, and that which has been dedicated to other than Allah. But whoever is forced [by necessity], neither desiring [it] nor transgressing [its limit], there is no sin upon him. Indeed, Allah is Forgiving and Merciful)). The carcass is any animal that itself is dead and in this verse, blood and pork are forbidden that the purpose of word meat was the pig's own animal because the meat forms most of the body. Any slaughter for non-God (for example, for idols) is forbidden. It is also understood from this verse that in the event of a state of emergency these prohibitions can also be permitted if the person is really in an emergency and does not exceed his limits and only consumes as much as it needs. And another important point in this verse is that it is expressed at the end of the verse: ((...Allah is Forgiving and Merciful)) this means that this permission to use these prohibitions in a state of emergency is in fact a forgiveness of God and it does not mean denying the sanctity of the forbidden items contained in the verse (Interpretation of Qareati). So far, there have been many harms in the use of pork Including dysentery, infectious jaundice, a red wind like disease that appears in humans in the form of red and painful spots with intense burning on the hands, atherosclerosis, joint pain and poisoning that is due to the high amount of fat and uric acid found in pork and the occurrence of a variety of parasitic agents, including Entamoeba histolithic [24-29]. There are even some disease that occurs just because of eating pork including a pig tapeworm found in the muscles and the brain of the pig and lead to suffer from gastrointestinal problems [30]. Because of pigs high economic cost and the high level of its breeding, the world's largest source of gelatin production is the pig and in most countries, people do not know at all what the source of gelatin or even the medicine (containing pork gelatin) they use is and swine gelatin is easily exported everywhere in a variety of ways and are used without consumer notice [31].

This research is a review and library study with focusing on interpretative texts and internet searches were performed by entering the keywords in the google scholar, PubMed, Magiran and science direct databases. The purpose of this study is to provide a variety of sources of gelatin production and examine them. We want to introduce vegetable and halal (meaning permitted in Islam) gelatin as a substitute for animal and haram (meaning prohibited in Islam) gelatin.

\section{Background research}

In 2013, Mariod et al. conducted a review of various types of gelatin and their sources for the presentation of various gelatins it was stated in this study that gelatins can be prepared from alternative sources such as fish except for pig and cattle [32]. Petrov et al., In a survey in 2015 to find out the properties of several types of gelatin for the manufacture of pharmaceutical capsules, concluded that the capsules prepared with collagen-derived gelatin had the highest concentrations (and only glycerol with water was added) while the lowest concentration was related to gelatin prepared from carrageenan [33]. In the 2013 Elzoghby review of the properties of gelatin as a carrier, especially for the production of carrier nanoparticles, gelatin was introduced as an important carrier of the drug as well as a substance used in gene therapy [34]. Bonilla et al. in 2016 examined a combination of gelatin and polysaccharide chitosan with several herbal extracts for their properties as food preservatives and showed that these compounds have antioxidant, antimicrobial and good preservative properties for all kinds of food [35]. In 2016, Al-Hassan determined the best properties of gelatin prepared from Greasy grouper fish in a study of gelatins derived from several types of fish as halal replacements for prohibited gelatins and even replacing bovine gelatin. Also, all gelatins of fish origin, prepared in this study showed better properties than bovine gelatin [36].

\section{Methodology}

Relevant articles were searched from Google Scholar, Pub Med, Scopus, Science direct, and Cochrane library. In the first search we obtain 406 articles, 183 articles were excluded in first screening for duplication and inappropriation of their content (this step was done by study on abstracts). Finally, 55 articles were included that matched with our subject.

\section{Animal gelatins}

Animal gelatins are derived from animal sources, especially pigs, cattle, and animals such as fish and poultry but due to more economic efficiency, they are mainly made from pigs or cows. However, the process of preparing gelatin from animal sources is a long and costly process because the meat, skin, and bone of the animal must first be prepared, and then crushes into small pieces and subsequently extracted for several weeks by different processes with a large amount of different chemicals [37-39].The mentioned operations are considered to be major disadvantages of animal gelatin in terms of industry because it takes a lot of time and money to prepare animal gelatin. Other great disadvantage of animal gelatin that, despite the vast efforts of companies and factories in the west to keep it secret is the entrance of pathogenic and harmful agents from animal meat and body to gelatin and the harmful effects of these gelatins with haram sources on the human body, that in recent years it is becoming clear [40,41]. 
Any researcher with a few minutes in academic and non-academic sources can easily find out that there are limited studies of swine gelatin and the number of articles on this subject is negligible while there are many articles even about the harms of fish gelatin.

\section{Swine gelatin}

Swine gelatin is extracted from the skin, flesh, bone and connective tissues of the pig's body. The only advantage of pig's gelatin is cost-effectiveness and the availability of its source and very high breeding [42]. If a suitable herbal or chemical source is discovered or invented for the production of gelatin, this advantage either disappears or becomes dimmed.

As it mentioned above, Allah prohibited eating pork in verse 173 of Surah Baqara, Allah also says in verse 115 of surah Nahl: ((He has only forbidden to you dead animals, blood, the flesh of swine, and that which has been dedicated to other than Allah. But whoever is forced [by necessity], neither desiring [it] nor transgressing [its limit] - then indeed, Allah is Forgiving and Merciful.)) also says in verse 145 of Surah Anam: ((Say, "I do not find within that which was revealed to me [anything] forbidden to one who would eat it unless it be a dead animal or blood spilled out or the flesh of swine - for indeed, it is impure - or it be [that slaughtered in] disobedience, dedicated to other than Allah. But whoever is forced [by necessity], neither desiring [it] nor transgressing [its limit], then indeed, your Lord is Forgiving and Merciful.")). Allah has mentioned four times straight to the prohibition of eating pork, which shows the great importance of this issue.

In the verse 114 of nahl surah says: ((Then eat of what Allah has provided for you [which is] lawful and good. And be grateful for the favor of Allah, if it is [indeed] Him that you worship)). As a result, Islam allows eating things that is both clean and halal; the comprehensive religion has also comprehensive orders. Both purity of appearance and intrinsic and legal purity (halal) is considered a condition of consumption (Interpretation of Qareati). Pure foods, unlike unpure foods, are foods that, while being halal, have good physical, psychological and spiritual effects. There are many quotes about eating pork. Imam Reza says to

Prohibit eating pork: ((God forbade eating the pig because it's a scary and ugly animal that God created him for the advice and learn [It means to realize that God is capable of anything and thanks God for the beauty of human face] and be afraid of lust and indifference that cause that God of Excellency has taken beautiful human face from them and make them like pigs [As he did with a population of predecessors in the world and others in the world of limbo and resurrection will be like pigs] and put the pig in the world of mankind to be a reason for its occuracne in before and other cause of pigs eating prohibition is that the pigs food is the most filthy and dirty trash with many corruptions and harmes in its blood)) (Horol ameli book, volume 16 page 378 ).

Also from a scientific point of view, pork has many pathogens and harms which can create many dangers for humans. Pigs are even an indifferent symbol for Europeans who eat it and considered as a dirty animal. The pigs are extremely indifferent and chaotic in sex, and in addition to the effect of food in morals that scientifically proved, the impact of this food is evident in sex carelessness. The animal has exposing its pair to other male pigs and it even delights in doing so. These traits have affect- ed its meat and so the people who feed on it get the same traits and morality [43-47]. Pigs do not have any interdiction to eat very dirty and contaminated things and even their stools, that's why the stomach is the place of variety kinds of germs that also spreads to its meat, blood and milk, therefore, many of these contaminants are also enter into swine products [48]. Because of the pig's lifestyle, feeding and its biological structure, the amount of antibodies produced by the body of this animal is greater than the rest also; the amount of growth hormones produced in the body is greater than the body of other animals and humans. This high level of antibody and growth hormone naturally enters the muscle tissue of the pig; in addition, pork has a very high level of cholesterol, other lipids, and uric acid which are very harmful to humans [49-51]. The problem with the use of this meat and its products in countries like the United States and Germany is now known. Important pathogens including viruses, bacteria and parasites are transferable to humans through pigs, these include:

Various studies show a strong relationship between pork consumption and gastric, prostate, breast, uterine, liver, and gallbladder cancer and other cancers [52-59]. Pork is also associated with the high levels of various fats and uric acid associated with many other diseases, including atherosclerosis, gout, and so on [60]. Swine and even cow gelatin because of certain $\operatorname{IgE}$ within them can cause very dangerous reactions, such as cross-reactions and allergies, especially in sensitive individuals. Several allergic reactions including anaphylaxis due to the administration of intravenous injection of swine gelatin based plasma substitutes has been reported so far [61]. Allergic reactions have been identified after using varicella and MMR vaccines actually is due to the excipient that made of swine gelatin [62]. Even systemic allergic reactions due to the use of substances containing such gelatins have seen, either as food or as medical products (such as suppositories). The expressed reactions are due to the specific IgE present in these gelatins. While Americans and Finns have reported that only about $27 \%$ and $14-28 \%$,respectively, of the systemic responses of children after vaccination with measles, mumps and rubella vaccines is due to swine gelatin specific IgE, Japanese researchers have shown that in $86 \%$ of the immediate-type hypersensitivity reactions in children vaccinated with vaccines containing these gelatins (measles, rubella, mumps, or chicken pox), swine gelatin specific IgE can be detected in their blood [63].

In addition, type I hypersensitivity reactions reported because of the swine specific IgE which even occurs at very low levels of this IgE. In this study it is mentioned that it is be better to consider the complications of swine and bovine gelatin than fish gelatin [64].

Other research suggests allergic reactions to this type of gelatin due to galactose-a-1, 3-galactose ( $\alpha$-Gal) that is in swine gelatin [35].

\section{Bovine gelatin}

Cow gelatin is also prepared just like swine gelatin, which has many of its properties and disadvantages. Bovine gelatin like swine gelatin has been used extensively and its source (meat and animal body) is why it still has a lot of mentioned risks especially if it slaughtered by non-Islamic way. Several researches suggest allergic reactions to bovine gelatin due to the presence of bovine gelatin specific IgE and $\alpha-G a l$ [66]. Another very important problem is that Bovine Madness Agent (BSE) is easily 
transmitted from the cow body into its gelatin because this is a very persistent prion and in the case of gelatin made from meat and even more difficult conditions it can still be transmitted to gelatin [67].

\section{Fish gelatin}

Fish gelatin is made from fish skin and bone with the aim of replacing prohibited or haram gelatin [68]. This type of gelatin also has its own limitations and complications including the fact that the source of it, that is, fish has not always been available everywhere, fish is also a valuable and expensive food, and it is not very economical to turn into gelatin [69]. Fish gelatin can also contain gelatin specific IgE and cause various allergies but it is much less than swine and bovine gelatin [70].

\section{Vegetable and Seaweed Source Gelatins}

Although in general, the word gelatin is referred to as a collagen-based jelly preparation made from animal tissues, but today, gelatin-like materials are prepared from vegetable sources with different formulations. They have very good properties; they are often very useful and not allergenic because almost all of them are made of safe and non-allergenic polysaccharides and the most important point is that herbal sources are halal. If a suitable herbal source for the production of gelatin be discovered, herbal gelatinous products can be substituted for animal gelatins particularly harmful and haram swine gelatin. Various researches on plant gelatins have proven their proper properties for the production of drugs [71-74].

\section{Agar}

Agar is a jelly material like herbal gelatins. The agar is made mostly of polysaccharide agarose, which is a supportive material in the cell wall of some seaweed and released by boiling [75]. These algae are known as agarophyte and they belong to the red algae race. The gelatin agar in fact is made up of two materials: the first linear polysaccharide agarose and the second heterogeneous mixture of smaller molecules called agaropectin [76]. Agar has been used extensively for microbiological testing and culture media preparation it can be used as a laxative and also as an appetite suppressant. Most importantly, it has all the applications of animal gelatins [77]. Agar is a substance that is indigestible by most organisms so can make a good culture medium that will not be destroyed by the growth of microbes. Agar contains some minerals and vitamins, including calcium, iron, zinc, potassium, magnesium, folate and high levels of fiber. It can also be useful for weight loss in obese people [78].

In general, agar is considered as a healthy and beneficial gelatin that so far, no allergic reactions or adverse effects have been reported, but because of its laxative property is not suitable for people with diarrhea. Despite its high benefits, due to the lack of resources, it is less economically efficient.

\section{Pectin}

Pectin is a structural heteropolysaccharide found in the primary cell wall of terrestrial plants. Pectin is commercially available in the form of a white to brown powder and mainly extracted from citrus [79]. Pectin has all the applications of animal gelatin in addition, it is considered as a fiber source. Chemically, pectin is rich in galacturonic acid and its maximum amount is in premature fruit [80]. Pectin is in fruits such as pears, apples, peaches, plums, oranges and other citrus fruits, while there are a small amount of pectin in soft fruits like cherries, grapes and strawberries. About $30 \%$ of orange peel is composed of pectin, while the edible portion of the orange has a range of 0.5 to $3.5 \%$ pectin. And a soft fruit like cherry have about $0.4 \%$ pectin [ 81 ]. Most of the production of pectin is from orange peel and apple scum that both of which are side products in the production of juice. The pectin production process is much faster and easier than animal gelatin [82]. Pectin has a high positive effect on the intestines and excretion in human, it also has the ability to dispose of heavy metals from body. Pectin has good properties for drug production and now it is used to produce some medications such as pastille pills. The use of pectin by the World Health Organization and the American Food and Drug Administration is known safe [83].

\section{Konjac}

It is a plant from family Araceae and in Japan, China, Korea and Myanmar is cultivated a comestible plant. This plant also has a jelly agent called konjac gelatin and used as an alternative gelatin for vegetarians. About $40 \%$ of konjac gelatin is made from glucomannan [84]. This gelatin alone has many healing properties, including detoxification, tumor suppression, blood stasis alleviation, and smooth the phlegm [85]. The gelatin made from the konjac is free from calories and has high fiber content instead and that's why it's suitable for people with diabetes, obese people, diabetics and many other people. Nourishing konjac gelatin increases the production of butyric acid from normal intestinal flora and improves gut movements [86]. One of the problems with this gelatin is its edible size because the jelly is not digested in the human body and if children eat a large piece of it, there is a risk of choking. Konjac gelatin oral intake results in less IgE production and reduces the risk of dermatitis [87].

\section{Carrageenan}

Carrageenan is a family of linear sulfate polysaccharides made from edible red algae. Carrageenan is a very suitable gelatinizing agent in the food industry and due to the high binding power it has with proteins, it is used in dairy and meat products. It is not used due to health hazards and concerns in pediatric products and pharmaceuticals [88].

\section{Conclusion}

Almighty Allah has always recommended humans to consume halal foods while avoiding haram foods. The Prophet of Allah says: "Avoid treating by haram.. He also says: "God has sent down pain and healing and sent healing for any pain, so treat yourself, but do not heal with haram." Imam Sadiq also states: "There is no healing in any haram. As it is seen, God has prevented people from being treated with haram what reaches other uses, Therefore, extensive research is required from the Islamic world to replace haram products with halal and Islamic products and our aim in this study was a comprehensive review of various types of sources, products and characteristics of different gelatins that in the near future, it will result in the production of halal gelatins with industrial and production advantages. Nowadays, from materials such as agar, pectin, carrageenan and konjac that are mentioned above, and as well as other materials, very good gelatins are prepared. And further researches are needed to find the rich sources of good gelatins or to find plants that have ap- 
propriate gelatin.

Along searching for valuable plants such as figs, grapes, olives, cedrus and ocimum basilicum, there were not found any articles or studies on the extraction or preparation of gelatin in various Internet sources, while for example; ocimum basilicum has a high jelly agent which, if wet, secretes it out. During searches about pomegranate it was found that its skin is a good source for extracting pectin [57].

\section{Authors' contribution}

All authors contributed equally to the manuscript.

\section{Conflicts of interest}

The authors declared no competing interests.

\section{Ethical considerations}

Ethical issues (including plagiarism, data fabrica $\neg$ tion, double publication and etc.) have been completely ob $\neg$ served by author.

\section{Funding/Support}

None.

\section{References}

1. Shaw G, Lee-Barthel A, Ross ML, et al. Vitamin C-enriched gelatin supplementation before intermittent activity augments collagen synthesis. Am J Clin Nutr. 2017 Jan 1; 105(1):136-43.

2. Mariod AA, Fadul H. gelatin, source, extraction and industrial applications. Acta Sci Pol Technol Aliment. 2013 Jun 30; 12(2):135-47.

3. Schortgen F, Lacherade JC, Bruneel F, et al. Effects of hydroxyethylstarch and gelatin on renal function in severe sepsis: a multicentre randomised study. The Lancet. 2001 Mar 24; 357(9260):911-6.

4. Hoque ME, Nuge T, Yeow TK, et al. Gelatin Based Scaffolds for Tissue Engineering-A Review. Polym Res J. 2015 Jan 1; 9(1):15.

5. Ishida K, Kuroda R, Miwa M, et al. The regenerative effects of platelet-rich plasma on meniscal cells in vitro and its in vivo application with biodegradable gelatin hydrogel. Tissue engin. 2007 May 1;13(5):1103-12.

6. Yang D, Li Y, Nie J. Preparation of gelatin/PVA nanofibers and their potential application in controlled release of drugs. Carbohydr Polym. 2007 Jun 25; 69(3):538-43.

7. Kantaria S, Rees GD, Lawrence MJ. Gelatin-stabilised microemulsion-based organogels: rheology and application in iontophoretic transdermal drug delivery. J Control Release. 1999 Aug 5; 60(2):355-65.

8. Ahmad T, Ismail A, Ahmad SA, et al. Recent advances on the role of process variables affecting gelatin yield and characteristics with special reference to enzymatic extraction: A review. Food Hydrocoll. 2017 Feb 28; 63:85-96.

9. Lee JH, Kim MR, Jo CH, et al. Specific PCR assays to determine bovine, porcine, fish and plant origin of gelatin capsules of dietary supplements. Food chem. 2016 Nov 15;211:253-9.

10. Serra IR, Fradique R, Vallejo MC, et al. Production and characterization of chitosan/gelatin/ $\beta$-TCP scaffolds for improved bone tissue regeneration. Materials Sci Engineering: C. 2015 Oct 1; 55: 592-604.

11. Sun J, Huang Y, Wang W, et al. Application of gelatin as a binder for the sulfur cathode in lithium-sulfur batteries. Electrochim Acta. 2008 Oct 15; 53(24):7084-8.

12. Lin $\mathrm{H}$, Cheng AW, Alexander PG, et al. Cartilage tissue engineering application of injectable gelatin hydrogel with in situ visible-light-activated gelation capability in both air and aqueous solution. Tissue Engineering Part A. 2014 Apr 7; 20(17-18):2402-11.

13. Prosekov A, Petrov A, Ulrich E, et al. Physical and Chemical Properties of Capsule Shell Based on Plant Analogues of Pharmaceutical Gelatin. Biol Med. 2015; 7(2): 2.

14. Hayakawt T, Mochizuki C, Amemiya T, et al. Bone response of gelatin composite including the apatite prepared from an amino acid calcium complex. J Oral Tissue Engin. 2015; 12(3):115-20.

15. Nakano $\mathrm{Y}$, Tobe $\mathrm{T}$, Choi-Miura $\mathrm{NH}$, et al. Isolation and characterization of GBP28, a novel gelatin-binding protein purified from human plasma. The J Biochem. 1996 Oct 1; 120(4):803-12.

16. Hanani ZN, Roos YH, Kerry JP. Use and application of gelatin as potential biodegradable packaging materials for food products. Int J Biol Macromol. 2014 Nov 30; 71: 94-102.

17. Licodiedoff S, Koslowski LA, Scartazzini L, et al. Conservation of physalis by edible coating of gelatin and calcium chloride. Intern Food Res J. 2016 Dec; 1: 23(4).

18. Kevadiya BD, Rajkumar S, Bajaj HC, et al. Biodegradable gelatin-ciprofloxacin-montmorillonite composite hydrogels for controlled drug release and wound dressing application. Colloids Surf B Biointerfaces. 2014 Oct 1; 122:17583.

19. Cui Q, Yashchenok A, Zhang L, et al. Fabrication of bifunctional gold/gelatin hybrid nanocomposites and their application. ACS Appl Mater Interfaces. 2014 Jan 16; 6(3):19992002.

20. Håkonsen H, Lees K, Toverud EL. Cultural barriers encountered by Norwegian community pharmacists in providing service to non-Western immigrant patients. Int J Clin Pharm. 2014 Dec 1; 36(6):1144-51.

21. Brown R. How Gelatin Becomes an Essential Symbol of Muslim Identity: Food Practice as a Lens into the Study of Religion and Migration. Religious Studies Theol. 2016; 1;35(2):185.

22. Robinson K, Hoey M. Religion and drugs. Student BMJ. 2009; $1 ; 17$.

23. Domínguez-Courtney MF, López-Malo A, Palou E, et al. Optimization of mechanical properties of carboxymethyl cellulose, carrageenan and/or xanthan gum gels as alternatives of gelatin softgels capsules. Optimization. 2015; 2(11): 2 .

24. Nanji A, French S. Relationship between pork consumption and cirrhosis. The Lancet. 1985 Mar 23; 325(8430):681-3.

25. Murphy KJ, Parker B, Dyer KA, et al. A comparison of regular consumption of fresh lean pork, beef and chicken on body composition: a randomized cross-over trial. Nutrients. 2014 Feb 14; 6(2):682-96.

26. Wang XQ, Terry PD, Cheng L, et al. Interactions between pork consumption, CagA status and IL-1B-31 genotypes in gastric cancer. World J Gastroenterol: WJG. 2014; 7; 20(25): 8151.

27. Gonwong S, Chuenchitra T, Khantapura P, et al. Pork consumption and seroprevalence of hepatitis E virus, Thailand, 2007-2008. Emerging Infec Dis. 2014; 20(9):1531.

28. [28] Bouvard V, Loomis D, Guyton KZ, et al. Carcinoge- 
nicity of consumption of red and processed meat. Lancet Oncol. 2015; 1; 16(16): 1599.

29. Song P, Lu M, Yin Q, et al. Red meat consumption and stomach cancer risk: a meta-analysis. Journal of cancer research and clinical oncology. J Cancer Res Clin Oncol. 201; 140(6):979-92.

30. Tuyet-Hanh TT, Sinh DX, Phuc PD, et al. Exposure assessment of chemical hazards in pork meat, liver, and kidney, and health impact implication in Hung Yen and Nghe An provinces, Vietnam. Int J Public Health. 2017; 1; 62(1):7582.

31. Sudjadi, Wardani HS, Sepminarti T, et al. Analysis of porcine Gelatin DNA in a commercial capsule shell using real-time polymerase chain reaction for halal authentication. Intern J Food Properties. 2016; 1; 19(9):2127-34.

32. Mariod AA, Fadul H. gelatin, source, extraction and industrial applications. Acta Sci Pol Technol Aliment. 2013; 30; 12(2):135-47.

33. Petrov A, Dyshlyuk L, Koroleva O, et al. Light Transmission Coefficient and the Thickness of Soft Capsule Shells Derived from Plant Analogs of Pharmaceutical Gelatin. Biol Med. 2015; 7(2): 2.

34. Elzoghby AO. Gelatin-based nanoparticles as drug and gene delivery systems: reviewing three decades of research. J Control Release. 2013; 28; 172(3): 1075-91.

35. Bonilla J, Sobral PJ. Investigation of the physicochemical, antimicrobial and antioxidant properties of gelatin-chitosan edible film mixed with plant ethanolic extracts. Food Biosci. 2016; 1; 16:17-25.

36. Al-Hassan AA. Extraction and Characterization of Halal Gelatin from Fish Skin. J Agricultural Vet Sci. 2016; 21; 9(1).

37. Mironova MM, Kovaleva EL. Comparative Analysis of Quality Assessment Requirements for Gelatin Used in Drug Production. Pharmaceutical Chem J. 2017; 1; 50(12):820-5.

38. Hoogenboom LA, Van Eijkeren JC, Zeilmaker MJ, et al. A novel source for dioxins present in recycled fat from gelatin production. Chemosphere. 2007; 30; 68(5):814-23.

39. Nicolas-Simonnot MO, Tréguer V, Leclerc JP, et al. Experimental study and modelling of gelatin production from bone powder: elaboration of an overall kinetic scheme for the acid process. Chem Engin J. 1997; 1; 67(1):55-64.

40. Asyakina LK, Belousova OS, Avstrievskih AN, et al. Study of organoleptic, physical-chemical and technological properties of the plant analogues of pharmaceutical gelatin production for soft capsules. Foods Raw Materials. 2015; 3(1): 6.

41. Jamaludin MA, Zaki NN, Ramli MA, et al. Istihalah: analysis on the utilization of Gelatin in food products. In2nd International Conference on Humanities, Historical and Social Sciences, IPEDR 2011 (17): 8.

42. Hafidz RM, Yaakob CM, Amin I, et al. Chemical and functional properties of bovine and porcine skin gelatin. Intern Food Res J. 2011; 18(2011):813-7.

43. Hess AS, Islam Z, Hess MK, et al. Comparison of host genetic factors influencing pig response to infection with two North American isolates of porcine reproductive and respiratory syndrome virus. Genetics Selection Evolution. 2016; 20; 48(1):43.

44. Niederwerder MC, Rowland RR. Is There a Risk for Introducing Porcine Reproductive and Respiratory Syndrome Virus (PRRSV) Through the Legal Importation of Pork?.
Food Environ Virol. 2017; 1; 9(1):1-3.

45. Jaques T. Cadbury and pig DNA: when issue management intersects with religion. Corporate Communications: An International Journal. 2015; 5; 20(4): 468-82.

46. Islam MT. Awareness, Emphasized on Swine Meat Consumption. Asian Journal of Ethnopharmacol Med Foods. 2016:11.

47. Curtis EE. Science and Technology in Elijah Muhammad's Nation of Islam. Nova Religio: The Journal of Alternative and Emergent Religions. 2016; 1; 20(1):5-31.

48. Barbin DF, ElMasry G, Sun DW, et al. Non-destructive assessment of microbial contamination in porcine meat using NIR hyperspectral imaging. Innovative Food Sci Emerging Technologies. 2013; 31; 17:180-91.

49. Mozzicato SM, Tripathi A, Posthumus JB, et al. Porcine or Bovine Valve Replacement in Three Patients with IgE Antibodies to the Mammalian Oligosaccharide Galactose-alpha-1, 3-Galactose. J Allergy Clin Immunol Pract. 2014; 2(5):637

50. Abente EJ, Santos J, Lewis NS, et al. The molecular determinants of antibody recognition and antigenic drift in the $\mathrm{H} 3$ hemagglutinin of swine influenza A virus. J Virol. 2016; 15; 90(18): 8266-80.

51. Vegosen L, Breysse PN, Agnew J,et al. Occupational Exposure to Swine, Poultry, and Cattle and Antibody Biomarkers of Campylobacter jejuni Exposure and Autoimmune Peripheral Neuropathy. PloS One. 2015; 4;10(12): 0143587.

52. Jones TH, Muehlhauser V. F-coliphages, porcine adenovirus and porcine teschovirus as potential indicator viruses of fecal contamination for pork carcass processing. Int J Food Microbiol. 2017; 16; 241: 237-43.

53. Pensaert MB, Sanchez RE, Ladekjær-Mikkelsen AS, et al. Viremia and effect of fetal infection with porcine viruses with special reference to porcine circovirus 2 infection. Vet Microbiol. 2004; 4; 98(2): 175-83.

54. Milios KT, Drosinos EH, Zoiopoulos PE. Food Safety Management System validation and verification in meat industry: Carcass sampling methods for microbiological hygiene criteria-A review. Food Contr. 2014; 30; 43:74-81.

55. Goyette-Desjardins G, Auger JP, Xu J, et al. Streptococcus suis, an important pig pathogen and emerging zoonotic agent-an update on the worldwide distribution based on serotyping and sequence typing. Emerg Microbes Infect. 2014; 3(6): 45.

56. Okello AL, Burniston S, Conlan JV, et al. Prevalence of endemic pig-associated zoonoses in southeast Asia: a review of findings from the Lao People's Democratic Republic. Am J Trop Med Hyg. 2015; 6; 92(5): 1059-66.

57. Gabriël S, Johansen MV, Pozio E, et al. Human migration and pig/pork import in the European Union: What are the implications for Taenia solium infections?. Vet Parasitol. 2015; 30; 213(1):38-45.

58. Papuc C, Goran GV, Predescu CN, et al. Mechanisms of oxidative processes in meat and toxicity induced by postprandial degradation products: A Review. Compr Rev Food Sci Food Saf. 2017; 1; 16(1): 96-123.

59. Schook LB, Collares TV, Darfour-Oduro KA, et al. Unraveling the swine genome: implications for human health. Annu Rev Anim Biosci. 2015; 3: 219-44.

60. McKenney ML, Schultz KA, Boyd JH, et al. Epicardial adipose excision slows the progression of porcine coronary 
atherosclerosis. J Cardiothorac Surg. 2014; 3; 9(1): 2.

61. Bogdanovic J, Halsey NA, Wood RA, et al. Bovine and porcine gelatin sensitivity in milk and meat-sensitized children. J Allergy Clin Immunol. 2009; 124(5):1108.

62. Martelli P, Ferrari L, Morganti M, et al. One dose of a porcine circovirus 2 subunit vaccine induces humoral and cell-mediated immunity and protects against porcine circovirus-associated disease under field conditions. Vet Microbiol. 2011; 5; 149(3): 339-51.

63. Pool V, Braun MM, Kelso JM, et al. Prevalence of anti-gelatin IgE antibodies in people with anaphylaxis after measles-mumps-rubella vaccine in the United States. Pediatrics. 2002 Dec 1; 110(6): 71-.

64. Sakaguchi M, Nakayama T, Inouye S. Food allergy to gelatin in children with systemic immediate-type reactions, including anaphylaxis, to vaccines. J Allergy Clin Immunol. 1996; 31; 98(6):1058-61.

65. Uyttebroek A, Sabato V, Bridts $\mathrm{CH}$, et al. Anaphylaxis to succinylated gelatin in a patient with a meat allergy: galactose- $\alpha(1,3)$-galactose ( $\alpha$-gal) as antigenic determinant. J Clin Anesth. 2014; 30; 26(7): 574-6.

66. Pinson ML, Waibel KH. Safe administration of a gelatin-containing vaccine in an adult with galactose- $\alpha-1,3$-galactose allergy. Vaccine. 2015; 3; 33(10): 1231-2.

67. Brown P, Will RG, Bradley R, et al. Bovine spongiform encephalopathy and variant Creutzfeldt-Jakob disease: background, evolution, and current concerns. Emerging infect Dis. 2001; 7(1): 6 .

68. [68] Karim AA, Bhat R. Fish gelatin: properties, challenges, and prospects as an alternative to mammalian gelatins. Food Hydrocoll. 2009; 31; 23(3):563-76.

69. Haug IJ, Draget KI, Smidsrød O. Physical and rheological properties of fish gelatin compared to mammalian gelatin. Food Hydrocoll. 2004; 31; 18(2):203-13.

70. Fujimoto W, Fukuda M, Yokooji T, et al. Anaphylaxis provoked by ingestion of hydrolyzed fish collagen probably induced by epicutaneous sensitization. Allergol Int. 2016; 65(4): 474-6.

71. Strauss G, Gibson SM. Plant phenolics as cross-linkers of gelatin gels and gelatin-based coacervates for use as food ingredients. Food Hydrocoll. 2004; 31; 18(1):81-9.

72. Rocasalbas G, Francesko A, Touriño S, et al. Laccase-assisted formation of bioactive chitosan/gelatin hydrogel stabilized with plant polyphenols. Carbohydr Polym. 2013; 15; 92(2):989-96.

73. Coetzee J, Merwe CF. Penetration rate of glutaraldehyde in various buffers into plant tissue and gelatin gels. J Microsc. $1985 ; 1 ; 137(2): 129-36$.

74. Yan M, Li B, Zhao X, et al. Physicochemical properties of gelatin gels from walleye pollock (Theragra chalcogramma) skin cross-linked by gallic acid and rutin. Food Hydrocoll. 2011; 31; 25(5):907-14

75. Frank D, Eyres GT, Piyasiri U, et al. Effects of agar gel strength and fat on oral breakdown, volatile release, and sensory perception using in vivo and in vitro systems. J Agric Food Chem. 2015; 13; 63(41): 9093-102.

76. Kumari A, Prasad A. Assessment of agar gel immunodiffusion test for seroprevalence of infectious bursal disease infection. Indian J Comparative Microbiol Immunol Infect Dis. 2015 ; 36(2): 90-1.

77. Zong Y, Han JH, Oh YJ, et al. Release Profile and Antimi- crobial Activity of Nisin Control-released from Agar Gel Foods. Food Engeen Prog. 2017; 28; 21(1): 36-41.

78. Wang Z, Yang K, Brenner T, et al. The influence of agar gel texture on sucrose release. Food Hydrocoll. 2014; 31; 36: 196-203.

79. Kay RM, Truswell AS. Effect of citrus pectin on blood lipids and fecal steroid excretion in man. Am J Clin Nutr. 1977; 1; 30(2):171-5

80. Mohnen D. Pectin structure and biosynthesis. Curr Opin Plant Biol. 2008 Jun 30; 11(3):266-77.

81. Thakur BR, Singh RK, Handa AK, et al. Chemistry and uses of pectin-a review. Crit Rev Food Sci Nutr. 1997; 1; 37(1): 47-73.

82. Grassino AN, Halambek J, Djaković S, et al. Utilization of tomato peel waste from canning factory as a potential source for pectin production and application as tin corrosion inhibitor. Food hydrocoll. 2016; 31; 52: 265-74.

83. Tkalec G, Knez Ž, Novak Z. Fast production of high-methoxyl pectin aerogels for enhancing the bioavailability of low-soluble drugs. J Supercritical Fluids. 2015; 31; 106:1622.

84. Li J, Wang Y, Jin W, et al. Application of micronized konjac gel for fat analogue in mayonnaise. Food Hydrocoll. 2014; 31; 35: 375-82.

85. Jimenez-Colmenero F, Cofrades S, Herrero AM, et al. Konjac gel for use as potential fat analogue for healthier meat product development: Effect of chilled and frozen storage. Food Hydrocoll. 2013; 31; 30(1): 351-7.

86. Jiménez-Colmenero F, Triki M, Herrero AM, et al. Healthy oil combination stabilized in a konjac matrix as pork fat replacement in low-fat, PUFA-enriched, dry fermented sausages. LWT-Food Sci Technol. 2013 Apr 30; 51(1): 158-63.

87. Li MY, Feng GP, Wang H, et al. Deacetylated Konjac Glucomannan Is Less Effective in Reducing Dietary-Induced Hyperlipidemia and Hepatic Steatosis in C57BL/6 Mice. J Agric Food Chem. 2017 Feb 17; 65(8): 1556-65.

88. Bhowmick B, Sarkar G, Rana D, et al. Effect of carrageenan and potassium chloride on an in situ gelling ophthalmic drug delivery system based on methylcellulose. RSC Advances. 2015; 5(74):60386-91. 